\title{
Screening of BCS1L mutations in severe neonatal disorders suspicious for mitochondrial cause
}

\author{
Vineta Fellman · Susanna Lemmelä · \\ Antti Sajantila $\cdot$ Helena Pihko $\cdot$ Irma Järvelä
}

Received: 5 November 2007/Accepted: 11 March 2008/Published online: 2 April 2008

(C) The Japan Society of Human Genetics and Springer 2008

\begin{abstract}
The BCSIL gene encodes a chaperone responsible for assembly of respiratory chain complex III (CIII). A homozygous point mutation $(232 \mathrm{~A} \rightarrow \mathrm{G})$ has been found as the genetic etiology for fetal growth retardation, amino aciduria, cholestasis, iron overload, lactic acidosis, and early death (GRACILE) syndrome (MIM 603358). Variable phenotypes have been found with other mutations. Our aim was to assess whether $232 \mathrm{~A} \rightarrow \mathrm{G}$ or other BCS1L mutations were present in infants $(n=21)$ of Finnish
\end{abstract}

Competing interest: nothing to disclose. Funding: the study was supported by grants from Medical Society of Finland (Finska Läkaresällskapet).

Electronic supplementary material The online version of this article (doi:10.1007/s10038-008-0284-0) contains supplementary material, which is available to authorized users.

V. Fellman $(\bowtie) \cdot$ H. Pihko

Hospital for Children and Adolescents, Helsinki University

Central Hospital, POB 281, 00029 Helsinki, Finland

e-mail: vineta.fellman@helsinki.fi

\section{Fellman}

Department of Pediatrics, Lund University,

Lund, Sweden

S. Lemmelä · I. Järvelä

Department of Medical Genetics, University of Helsinki,

Helsinki, Finland

\section{A. Sajantila}

Department of Forensic Medicine,

University of Helsinki, Helsinki, Finland

I. Järvelä

Laboratory of Molecular Genetics, Helsinki

University Central Hospital, Helsinki, Finland origin with severe, lethal disease compatible with mitochondrial disorder. A further aim was to confirm the GRACILE genotype-phenotype constancy $(n=8)$. Three new cases with homozygous $232 \mathrm{~A} \rightarrow \mathrm{G}$ mutation were identified; all had the primary GRACILE characteristics. No other mutations were found in the gene in other cases. All infants with GRACILE syndrome had the typical mutation. In conclusion, the rather homogenous population of Finns seems to have a specific BCSIL mutation that, as homozygous state, causes GRACILE syndrome, whereas other mutations are rare or not occurring. Thus, the novel clinical implication of this study is to screen for BCS1L mutations only if CIII is dysfunctioning or lacking Rieske protein, and to assess $232 \mathrm{~A} \rightarrow \mathrm{G}$ mutation in cases with GRACILE syndrome.

Keywords Encephalopathy - Metabolic brain disease . Fetal growth retardation - Lactic acidosis .

Respiratory chain complex III

\section{Introduction}

The expanding research over recent years in mitochondrial disorders has revealed a wide spectrum of underlying pathogenetic mechanisms and subsequently large variations in disease presentation (Di Mauro and Schon 2003). Further, different clinical pictures of a mutation in the same disease-causing gene may result from varying cellular and tissue expression of the defect. In infancy, mitochondrial dysfunction would primarily be expected in organs that utilize large amounts of energy, such as the heart, brain, and muscle. Thus, mitochondrial disorder should be suspected in cases of neonatal death; in infants with postnatal metabolic acidosis, cardiomyopathy, or encephalopathy; or 
severe failure to thrive (Scaglia et al. 2004; Fellman 2006; Robinson 2006). These findings, isolated or in combination, occur in respiratory chain complex III (CIII) diseases, which are less prevalent than those of the other respiratory complexes (Scaglia et al. 2004). Genetic defects causing CIII deficiency include mutations in the only mitochondrial DNA-encoded CIII subunit cytochrome $b$, other mitochondrial DNA abnormalities, mutation in one of the nuclearly encoded subunits (subunit 7, UQCRB), as well as mutations in the assembly protein BCSIL (NM 004328) (Valnot et al. 1999; Haut et al. 2003; Fellman 2006).

We have shown that a homozygous missense mutation $(232 \mathrm{~A} \rightarrow \mathrm{G})$ in exon 2 , i.e., the first protein-coding exon, of $B C S I L$, resulting in a serine to glycine amino acid exchange at codon 78 (S78G), is the cause of GRACILE syndrome (Fellman's syndrome, MIM 603358), an autosomal recessive fatal disease of newborns (Fellman et al. 1998; Visapää et al. 2002). The acronym stands for the typical clinical findings (fetal growth restriction, aminoaciduria due to proximal tubulopathy, cholestasis, iron overload with considerable liver hemosiderosis, severe lactacidosis, and early death) and alludes to the slender appearance of the infants. No evident neurological abnormality has been found during their short life span of at most 4 months (Fellman et al. 1998). In other populations, different mutations in the $B C S I L$ gene have resulted in variable infant phenotypes with survival up to even 9 years (Morris et al. 1995; De Lonlay et al. 2001; De Meirleir et al. 2003). Of three British infants with CIII deficiency, we found a compound heterozygote with S78G and a substitution of arginine to glutamine at codon 144 (R144Q) presenting with a milder disease than typical for GRACILE; the infant was hypotonic, developed liver dysfunction, and died after 15 weeks (Visapää et al. 2002). The other two cases were also compound heterozygotes with BCSIL mutations, causing a phenotype of normal liver histology with seizures and hypotonia in one and cholestasis and neuropathological findings in the other (Visapää et al. 2002). In newborn infants of Turkish origin with CIII deficiency, compound heterozygous as well as two different homozygous mutations in exons 2 and 4, respectively, were found as the etiology (De Lonlay et al. 2001). All had lactic acidosis and tubulopathy; however, the birth weight was normal or only slightly decreased, liver symptoms were variable, and typically they had significant encephalopathy, compatible with Leigh syndrome in one case (De Lonlay et al. 2001). In a Spanish family, two infants with severe postnatal lactic acidosis associated with CIII deficiency had a heterozygous mutation in exon 2 causing a substitution of arginine to cysteine at codon 45 (R45C) and a premature stop at codon 56 (R56X) (De Meirleir et al. 2003). Both had hepatic dysfunction and tubulopathy but only moderate growth restriction.
As different $B C S 1 L$ mutations have resulted in variable neonatal phenotypes, we hypothesized that the $232 \mathrm{~A} \rightarrow \mathrm{G}$ mutation enriched in the Finnish population might in compound heterozygotes cause variable phenotypes and that other BCSIL mutations may result in other phenotypes. Further, we wanted to verify that all cases with GRACILE syndrome have the homozygous S78G mutation. Thus, our objectives were to assess the $232 \mathrm{~A} \rightarrow \mathrm{G}$ mutation in cases with suspicion of mitochondrial disorders, and if not found, to sequence the entire gene.

\section{Materials and methods}

\section{Patients}

The study was approved by the local ethics committee. Infants referred to the Hospital for Children and Adolescents, Helsinki University Hospital, Helsinki, Finland, for diagnostic investigations of serious metabolic or neurological disorder leading to death during infancy or childhood were included in this patients series if they fulfilled modified Walker minor clinical criteria (Scaglia et al. 2004) and belonged to one of three disease groups: (1) a considerable postnatal lactic acidosis or an unexpected metabolic catastrophe suggestive of mitochondrial disease, (2) a severe cholestatic liver dysfunction of unknown origin, or (3) encephalopathy of unknown origin born to a family with at least one previous similar case. The responsible clinician had performed diagnostic workup with inconclusive results and preserved paraffin tissue samples or fibroblasts with parental consent. Twenty-one infants with suspicion of mitochondrial disease were identified from 15 families (Table 1). In the encephalopathy group, only one case per family was sequenced for the whole $B C S 1 L$ gene.

In addition, we studied the gene in eight infants with GRACILE phenotype (Fellman et al. 1998), five of whom were prospectively enrolled in the 2000s. Written informed parental consent was obtained prior to enrollment.

\section{PCR sequencing}

DNA was extracted from fibroblasts $(n=11)$, from paraffin-embedded blocks of tissue samples $(n=9)$, and from leucocytes in prospectively collected GRACILE cases $(n=5$; Table 2$)$. As we did not get sufficient high-quality polymerase chain reaction (PCR) products from all fragments, only a fragment of the first protein-coding exon (exon 2) of the BCSIL gene containing the previously identified Finnish mutation $232 \mathrm{~A} \rightarrow \mathrm{G}$ (Visapää et al. 2002) was analyzed in six cases. The entire gene was sequenced in 11 cases without this mutation. Primer sequences are shown on the online Table (S1). 
Table 1 Clinical characteristics of patients with suspicion of mitochondrial disease assigned to groups according to the main presenting finding

\begin{tabular}{llll}
\hline & $\begin{array}{l}\text { Acidosis } \\
\text { early death }\end{array}$ & $\begin{array}{l}\text { Hepatopathy } \\
\text { early death }\end{array}$ & Encephalopathy \\
\hline Families & 8 & 3 & 4 \\
Patients & 9 & 3 & 9 \\
Male & 2 & 2 & 3 \\
Metabolic acidosis & 9 & 1 & 1 \\
Tubulopathy & 2 (of 4 studied) & 1 & None \\
Liver failure & None & 3 & 3 \\
Neurological symptoms & None & 1 & 9 \\
& Median (range) & Range & Median (range) \\
Gestational age, weeks & $37(28-42)$ & $31-41$ & 40 (38-42) \\
Birth weight, g & $1,440(620-3,550)$ & $780-3,400$ & $3,340(2,300-$ \\
& & & $4,000)$ \\
Standard deviation score & $-3.9(-5.2$ to 0$)$ & -4 to 0.3 & 0 (-2.4 to 1) \\
Apgar at 1 min & $8(7-9)$ & $7-10$ & 9 (8-9) \\
Age at death, days & $59(2-160)$ & $8-74$ & 135 (78-653) \\
$B C S 1 L$ sequenced, $n$ & 6 & 1 & 4 \\
\hline
\end{tabular}

PCR amplifications were performed in a $25-\mu$ l volume containing 100-150 ng genomic DNA, 15 pmol of each primer, $0.2 \mu \mathrm{M}$ of each nucleotide, 0.25 or $0.75 \mathrm{mM}$ $\mathrm{MgCl}_{2}, 200 \mathrm{mM}$ Tris- $\mathrm{HCl}$ (pH 8.4), $500 \mathrm{mM} \mathrm{KCl}$, and $1 \mathrm{U}$ Platinum Taq DNA polymerase enzyme or Dynazyme (Finnzymes, Espoo, Finland). Amplification was performed with an MJ Research thermocycler (Cambridge, MA, USA). PCR conditions were as follows: $2 \mathrm{~min}$ at $95^{\circ} \mathrm{C}$; followed by 39 cycles of denaturation, $30 \mathrm{~s}$ at $94^{\circ} \mathrm{C}$; annealing, $35 \mathrm{~s}$ at temperature specific for each primer $\left(55-62^{\circ} \mathrm{C}\right)$; elongation, $1 \mathrm{~min}$ at $72^{\circ} \mathrm{C}$; and final extension for $10 \mathrm{~min}$ at $72^{\circ} \mathrm{C}$. The specificity of the PCR products was assessed by $1.5 \%$ agarose gel electrophoresis. Sequencing was performed using cycle sequencing with Big Dye Terminator kit (version 3.1) supplied by Applied Biosystems (ABI, Foster City, CA, USA), and reactions were run on an ABI 3730 automatic DNA sequencer according to the manufacturer's instructions. Sequence analyses were performed with Sequencher 4.0.5 software (Gene Codes Corporation, Ann Arbor, MI). The $232 \mathrm{~A} \rightarrow \mathrm{G}$ mutation of the patients with GRACILE syndrome (Table 2) was analyzed at the Laboratory of Molecular Genetics, Helsinki University Hospital by minisequencing (Visapää et al. 2002; Syvänen et al. 1990). Primers are available from authors by request.

\section{Results}

In the series of infants with suspicion of mitochondrial disease, three cases with the typical homozygous $232 \mathrm{~A} \rightarrow \mathrm{G}$ mutation was found in the metabolic acidosis group. Two were twin sisters treated in the neonatal intensive care unit until death because of metabolic disease. No data were available regarding renal tubulopathy or iron metabolism.
The third infant was born small for gestational age, developed lactic acidosis and tubulopathy, and died at 5 days of age. Thus, they had the typical presenting findings of GRACILE syndrome, intrauterine growth restriction [born at 37 gestational weeks, the birth weight ranged 1,290$1,500 \mathrm{~g}$ and its standard deviation (SD) score -4.1 to -4.7$]$, metabolic acidosis, and early death (5 days to 4 months).

In the other groups, the $232 \mathrm{~A} \rightarrow \mathrm{G}$ mutation was not found. Neither did the entire BCS1L gene sequencing reveal any rearrangements in the infants studied (Table 1). Four cases had the common variation, rs2303561, reported from African as well as European and Asian populations (http://www.ncbi.nlm.nih.gov/), in a heterozygous form in intron 6 of the BCSIL gene.

All eight infants with GRACILE syndrome characteristics had the homozygous $232 \mathrm{~A} \rightarrow \mathrm{G}$ mutation (Table 2). During the 5-year period since publication of the mutation (Visapää et al. 2002) and access to antenatal screening in families with previous cases, four new patients were diagnosed in Finland, corresponding to an incidence of 1:70,000 newborns in this country.

\section{Discussion}

Expectedly, we found a consistent genotype-phenotype correlation in all infants presenting with the six main characteristics of GRACILE syndrome. Further, in the patient series with lethal metabolic disorder, the $232 \mathrm{~A} \rightarrow \mathrm{G}$ homozygous mutation was found only in cases with the most obvious signs of the syndrome, i.e., growth restriction, lactic acidosis and early death (Fellman et al. 1998). When the infants were born, the syndrome had not been delineated; thus, all characteristics were not investigated. 
Table 2 Clinical data of infants with GRACILE syndrome (five enrolled prospectively, numbers indicated when values missing). Tubulopathy was diagnosed in six infants

\begin{tabular}{|c|c|c|c|}
\hline & \multicolumn{3}{|c|}{ Patients $(n=8)$} \\
\hline & Median & Range & $\begin{array}{l}\text { Reference } \\
\text { value }\end{array}$ \\
\hline \multicolumn{4}{|l|}{ Birth data } \\
\hline $\begin{array}{l}\text { Gestational age, } \\
\text { weeks }\end{array}$ & 40.1 & $31.1-42$ & \\
\hline Birth weight, $g$ & 2,250 & $825-2,450$ & \\
\hline $\begin{array}{l}\text { Standard deviation } \\
\text { score }\end{array}$ & -3.2 & -5.2 to -2.8 & \\
\hline Birth height, $\mathrm{cm}$ & 45.5 & $35-48.5$ & \\
\hline Apgar at $1 \mathrm{~min}$ & 9 & $4-10$ & \\
\hline \multicolumn{4}{|l|}{ Acidosis } \\
\hline $\begin{array}{l}\mathrm{pH}, \text { at admission } \\
(n=7)\end{array}$ & 7.09 & $6.97-7.22$ & $7.35-7.43$ \\
\hline $\begin{array}{l}\text { Base deficit, at } \\
\text { admission }(n=6)\end{array}$ & 21 & $15-25$ & $-5 ; 5$ \\
\hline $\begin{array}{l}\text { Lactate, } \mathrm{mmol} / \mathrm{l} \\
(n=6)\end{array}$ & 14 & $9-27$ & $0.7-1.8$ \\
\hline $\begin{array}{l}\text { Lactate/pyruvate } \\
(n=6)\end{array}$ & 121 & $55-240$ & $<25$ \\
\hline \multicolumn{4}{|l|}{ Liver function } \\
\hline ASAT, U/1 $(n=5)$ & 171 & $63-232$ & $<80$ \\
\hline ALAT, U/1 $(n=5)$ & 91 & $35-108$ & $<40$ \\
\hline \multicolumn{4}{|l|}{ Serum iron chemistry } \\
\hline Iron, $\mu \mathrm{mol} / 1(n=5)$ & 16 & $4-26$ & $19-48$ \\
\hline $\begin{array}{l}\text { Transferrin, } \mathrm{g} / \mathrm{l} \\
(n=3)\end{array}$ & 0.8 & $0.6-1.2$ & $1.1-1.8$ \\
\hline $\begin{array}{l}\text { Transferrin iron } \\
\text { saturation, } \\
\text { percentage } \\
(n=4)\end{array}$ & 91 & $50-100$ & $30-60$ \\
\hline Ferritin, $\mu \mathrm{g} / \mathrm{l}(n=5)$ & 1,610 & $425-17,600$ & $<150$ \\
\hline Age at death, days & 36 & $1-93$ & \\
\hline
\end{tabular}

ASAT aspartate aminotransferase, ALAT alanine aminotransferase

The genotype-phenotype constancy is further supported by the finding that the $232 \mathrm{~A} \rightarrow \mathrm{G}$ mutation was not found in an additional 11 patients, who were studied because they had some but not all GRACILE symptoms (data not shown). As only paraffin-embedded tissue samples were available, the entire gene was not sequenced in them. In an unselected sample of 500 Finns, we previously found the carrier prevalence of the $232 \mathrm{~A} \rightarrow \mathrm{G}$ mutation to be 1:500 (Visapää et al. 2002). The prevalence in other populations is unknown; however, affected newborns with this mutation have been found both in Sweden (Fellman et al. 2002) and the UK (Visapää et al. 2002).

During embryonic development in mice, we have shown a different expression pattern of bcs1l compared with other mitochondrial proteins with abundance in neural structures deriving from the floor plate, suggesting another intracellular location and function than the reported chaperone action (Kotarsky et al. 2007). In published CIII deficiencies due to BCS1L mutations other than S78G, encephalopathy was found in five out of nine newborn infants (Morris et al. 1995; De Lonlay et al. 2001; De Meirleir et al. 2003), in one child with Björnstad syndrome (Hinson et al. 2007) and in the two children most recently reported (FernandezVizarra et al. 2007). Thus, a mutation of BCSIL could have been anticipated in our encephalopathy group, albeit there were no signs of metabolic acidosis in the majority of the infants. However, we found no compound heterozygotes in them or the other disorder groups, which suggests that gene screening is indicated only in cases with proven $B C S 1 L$ dysfunction. As $B C S 1 L$ as a chaperone facilitates the incorporation of Rieske FeS protein to CIII precomplex, CIII lacking Rieske protein suggests $B C S I L$ dysfunction (Nobrega et al. 1992; Cruciat et al. 1999). This assembly defect of CIII can be assessed with the blue-native polyacrylamide gel electrophoresis (BN-PAGE) method (Van Coster et al. 2001). Unfortunately, samples for such analyses of target tissues were not available in our patients.

Our rationale to study the $B C S 1 L$ gene in different clinical phenotypes was the previously observed phenotypic heterogeneity among BCSIL mutations in newborns (Morris et al. 1995; De Lonlay et al. 2001; De Meirleir et al. 2003). The importance of taking into account not only lactic acidosis but also clinical findings as indicator of possible mitochondrial disorder has been emphasized (Robinson 2006). Interestingly, a recent publication ascribed the Björnstad syndrome of congenital sensorineural deafness combined with hair disorder (pili tortis) to different heterozygous mutations in the BCSIL gene (Hinson et al. 2007). The contradiction between the mild phenotype in that syndrome, compatible with normal life without signs of CIII deficiency (Hinson et al. 2007), and the severe disease in all previously described BCSIL mutations might be explained by different protein formation on one hand and by respiratory supercomplexes that compensate CIII deficiency on the other (D'Aurelio et al. 2006). In another recent report, mutations in the BCSIL gene were found at 4 years of age in two unrelated children with an isolated defect of CIII activity and encephalopathy (Fernandez-Vizarra et al. 2007).

Well-defined phenotype-genotype correlations increases understanding of the disease and enables development of diagnostic tools. In contrast to many monogenic disorders (Dipple et al. 2001), the clinical phenotype caused by mutations in $B C S 1 L$ is very variable. Variations in phenotypes may be ascribed to modifier genes, system dynamics, or functional activity thresholds (Dipple and McCabe 2000). Thus, the distinct genotype-phenotype correlation found in a total of 31 infants, including those previously diagnosed (Fellman 2002), between BCS1L 
$232 \mathrm{~A} \rightarrow \mathrm{G}$ homozygous mutation and GRACILE syndrome, is interesting, suggesting a threshold model without an effect of modifier gene. Explanation for the mechanism of the rather mild disorder of Björnstad's syndrome without any proven CIII deficiency remains to be clarified (Hinson et al. 2007).

One of the strengths in this study was the possibility to study cases with a similar genetic background. Finland had an isolated population for centuries and thus became prone to founder effect for genetic disorders (Norio 2003). Using old paraffin blocks of tissue samples and short primers, we were able to assess the exon of highest priority and thus determine the diagnosis of deceased infants after a considerable time period.

In conclusion, the GRACILE phenotype-genotype correlation is consistent with an estimated present incidence of 1:70,000 live births. No other BCSIL mutations causing severe disorders in infancy are likely in the Finnish population. The clinical implications are, on one hand, to screen for mutations in the BCSIL gene only if CIII is deficient or lacking Rieske FeS protein, and on the other hand, to assess $232 \mathrm{~A} \rightarrow \mathrm{G}$ mutation in cases with GRACILE syndrome. The need for saving adequate samples, i.e., fibroblasts, from cases with unknown severe disorders, in appropriately established biobanks is a prerequisite for later possibility to assess the diagnosis.

Acknowledgments We acknowledge Kari Raivio and Tuula Lönnqvist for providing DNA from some patients.

\section{References}

Cruciat CM, Hell K, Fölsch H, Neupert W, Stuart RA (1999) Bcs1p, an AAAfamily member, is a chaperone for the assembly of the cytochrome bc1 complex. Embo J 18:226-233

D́Aurelio M, Gajewski CD, Lenaz G, Manfredi G (2006) Respiratory chain supercomplexes set the threshold for respiration defects in human mtDNA mutant cybrids. Hum Mol Genet 15:2157-2169

De Lonlay P, Valnot I, Barrientos A, Gorbatyuk M, Tzagoloff A, Taanman JW, Benayoun E, Chretien D, Kadhom N, Lombes A, de Baulny HO, Niaudet P, Munnich A, Rustin P, Rötig A (2001) A mutant mitochondrial respiratory chain assembly protein causes complex III deficiency in patients with tubulopathy, encephalopathy and liver failure. Nat Genet 29:57-60

De Meirleir L, Seneca S, Damis E, Sepulchre B, Hoorens A, Gerlo E, Garcia Silva MT, Hernandez EM, Lissens W, Van Coster R (2003) Clinical and diagnostic characteristics of complex III deficiency due to mutations in the BCS1L gene. Am J Med Genet 121:126-131

Di Mauro S, Schon EA (2003) Mechanisms of disease: mitochondrial respiratory-chain diseases. N Engl J Med 348:2656-2668

Dipple KM, McCabe ER (2000) Modifier genes convert "simple" Mendelian disorders to complex traits. Mol Genet Metab 71:43-50

Dipple KM, Phelan JK, McCabe ER (2001) Consequences of complexity within biological networks: robustness and health, or vulnerability and disease. Mol Genet Metab 74:45-50

Fellman V, Rapola J, Pihko H, Varilo T, Raivio KO (1998) Iron overload disease in infants involving fetal growth retardation, lactic acidosis, liver haemosiderosis, and aminoaciduria. Lancet 351:490-493

Fellman V (2002) The GRACILE syndrome, a neonatal lethal metabolic disorders with iron overload. Blood Cells Mol Dis 29:444-450

Fellman V, Visapää I, Vujic M, Wennerholm U-B, Peltonen L (2002) Antenatal diagnosis of hereditary fetal growth retardation with aminoaciduria, cholestasis, iron overload, and lactic acidosis in the newborn infant. Acta Obstetr Gynecol Scand 81:398-402

Fellman V (2006) Respiratory complex III deficiencies in the newborn infant. Drug Disc Dis Mech 3:421-427

Fernandez-Vizarra E, Bugiani M, Goffrini P, Carrara F, Farina L, Procopio E, Donati A, Uziel G, Ferrero I, Zeviani M (2007) Impaired complex III assembly associated with BCS1L gene mutations in isolated mitochondrial encephalopathy. Hum Mol Genet 6:1241-1252

Haut S, Brivet M, Touati G, Rustin P, Lebon S, Garcia-Cazorla A, Saudubray JM, Boutron A, Legrand A, Slama A (2003) A deletion in the human QP-C gene causes a complex III deficiency resulting in hypoglycaemia and lactic acidosis. Hum Genet 113:118-122

Hinson JT, Fantin VR, Schonberger J, Breivik N, Siem G, McDonough B, Sharma P, Keogh I, Godinho R, Santos F, Esparza A, Nicolau Y, Selvaag E, Cohen BH, Hoppel CL, Tranebjaerg L, Eavey RD, Seidman JG, Seidman CE (2007) Missense mutations in the BCS1L gene as a cause of the Bjornstad syndrome. N Engl J Med 356:809-819

Kotarsky H, Imran T, Mannisto S, Heikinheimo M, Hansson S, Fellman V (2007) BCS1L is expressed in critical regions for neural development during ontogenesis in mice. Gen Expr Patterns 3:266-273

Morris AAM, Taylor RW, Birch-Manin MA, Jackson MJ, Coulthard MG, Bindoff LA, Welch RJ, Howell N, Turnbull DM (1995) Neonatal Fanconi syndrome due to deficiency of complex III of the respiratory chain. Pediatr Nephrol 9:407-411

Nobrega FG, Nobrega MP, Tzagoloff A (1992) BCS1, a novel gene required for the expression of functional Rieske iron-sulfur protein in Saccharomyces cerevisiae. Embo J 11:3821-3829

Norio R (2003) Finnish disease heritage I: characteristics, causes, background. Hum Genet 112:441-456

Robinson BH (2006) Lactic acidemia and mitochondrial disease. Mol Genet Metab 89:3-13

Scaglia F, Towbin JA, Craigen WJ, Belmont JW, ÓBrian Smith E, Neish SR, Ware SM, Hunter JV, Fernbach SD, Vladutiu GD, Wong LJC, Vogel H (2004) Clinical spectrum, morbidity, and mortality in 113 pediatric patients with mitochondrial disease. Pediatrics 114:925-931

Syvänen AC, Aalto-Setala K, Harju L, Kontula K, Soderlund H (1990) A primer-guided nucleotide incorporation assay in the genotyping of apolipoprotein E. Genomics 8:684-692

Valnot I, Kassis J, Chretien D, de Lonlay P, Parfait B, Munnich A, Kachaner J, Rustin P, Rotig A (1999) A mitochondrial cytochrome $\mathrm{b}$ mutation but no mutations of nuclearly encoded subunits in ubiquinol cytochrome c reductase (complex III) deficiency. Hum Genet 104:460-406

Van Coster R, Smet J, George E, De Meirleir L, Seneca S, Van Hove J, Sebire G, Verhelst H, De Bleecker J, Van Vlelm B, Verloo P, Leroy J (2001) Blue native polyacrylamide gel electrophoresis: a powerful tool in diagnosis of oxidative phosphorylation defects. Pediatr Res 50:658-665

Visapää I, Fellman V, Vesa J, Dasvarma A, Hutton JL, Kumar V, Payne GS, Makarow M, van Coster R, Taylor RW, Turnbull DM, Suomalainen A, Peltonen L (2002) GRACILE syndrome, a lethal metabolic disorder with iron overload, is caused by a point mutation in BCS1L. Am J Hum Genet 4:863-876 